\title{
Comparison of Resilience, Cognitive Emotion Regulation and Metacognitive Beliefs of Primiparous and Multiparous Women
}

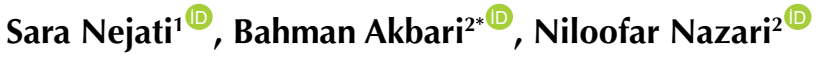 \\ ${ }^{1}$ Department of Psychology, Roudehen Branch, Islamic Azad University, Roudehen, Iran \\ ${ }^{2}$ Department of Psychology, Rasht Branch, Islamic Azad University, Rasht, Iran
}

\begin{abstract}
Background: The aim of this present study was the comparison of resilience, cognitive emotion regulation, and metacognitive beliefs of primiparous and multiparous women in Rasht.

Methods: The current research was a cross-sectional analytic study. The participants of this research were all of the primiparous and multiparous women who referred to Rasht hospitals between June and October in 2016. A total of 120 persons (60 primiparous and 60 multiparous women) selected by the random clustering sampling method. The Connor-Davidson resilience scale assessed the participants, cognitive emotion regulation questionnaire by Granfsky et al and Wells et al. metacognition questionnaire. Data analysis have done by using the multivariate variance analysis by SPSS v. 22 software.

Results: The findings showed that there were significant differences in resilience, cognitive emotion regulation, and metacognitive beliefs between primiparous and multiparous women $(P<0.001)$.

Conclusion: The results illustrated that there were significant differences in primiparous and multiparous women in resilience, cognitive emotion regulation, and metacognitive beliefs. It seems that training and practical steps to upgrade them as necessary.

Keywords: Resilience; Cognitive emotion regulation; Metacognitive beliefs; Pregnancy.
\end{abstract}

*Correspondence to Bahman Akbari, Associate Professor, Department of Psychology, Rasht Branch, Islamic Azad University, Rasht, Iran.

Tel: 0133342 3308; Email: Bakbari44@yahoo.com

Published online September 23, 2019

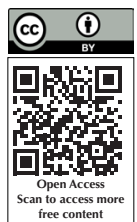

Citation: Nejati S, Akbari B, Nazari N. Comparison of resilience, cognitive emotion regulation and metacognitive beliefs of primiparous and multiparous women. Int Clin Neurosci J. 2019;6(4):146-150. doi:10.15171/icnj.2019.27.

\section{Introduction}

Childbirth is a natural event and has long antecedence. ${ }^{1}$ Various factors such as therapeutical interventions, fatigue, drugs, womb tension, and finally, mother's anxiety are known as first childbirths experiences. ${ }^{2}$ Resilience is known as a human adjustment ability against events, overcoming, and be reinforced by related experiences. This state expanded by human internal ability and social skills and has shown as a positive trait. ${ }^{3}$ According to Werner and Smith, resilience is the human self-adjustment natural mechanism and believes that persons with more resilience have more flexible than others. ${ }^{4}$ Shebi and Ghafari research showed that there is a significant difference in the resilience level of pregnant \& un-pregnant women. ${ }^{5}$ According to Modaress et al, there is a significant relationship among baby feed, problems related to baby caring baby, weight, and mental factors such as life stressful events with childbirth traumatic stress disorder. ${ }^{6}$ Emotion cognitive regulation is essential for the researcher because of little research about its role in childbirth experience. Persons adjust their emotions consciously or unconsciously by emotion cognitive adjustment. ${ }^{7}$ Persons always use systematic strategies to adjust the severity of their emotional experiences. Successful regulation of emotion is related to health consequences, interpersonal communications, consistent occupational performance. ${ }^{8}$ Cognitive regulation of emotion refers to the cognitive method of emotion stimulating information management. ${ }^{9}$ On the other words, cognitive regulation strategies of emotion refers to the way of persons thought after a negative experience. ${ }^{10}$ According to Troy and Mauss, a person's ability in the regulation of their emotions may be an essential factor in determining their resilience. ${ }^{11}$ Cognitive regulation of emotion includes using cognitive-behavioral strategies to change an emotion experience severity. Metacognitive believes known as the other active factors upon childbirth. ${ }^{12}$ This model to explain mind-controlling consists of 2 parts: cognitive activity and metacognition (it adjusts and assesses this cognitive activity). Metacognition consists of a person's believes about self, metacognitive experiences, and metacognitive strategies. ${ }^{13}$ According to the research records, negative metacognition believes about being uncontrollable, and anxiety may predict

(C) 2019 The Author(s). This is an open access article distributed under the terms of the Creative Commons Attribution License (http:// creativecommons.org/licenses/by/4.0/), which permits unrestricted use, distribution, and reproduction in any medium, provided the original work is properly cited. 
depression and anxiety significantly. ${ }^{14}$ The reason for many mental disorders of pregnant women is related to being unfamiliar with natural changes in pregnancy. Therefore, young persons need more instruction and attitude change toward pregnancy. No research has done about this subject in our country. Therefore, this research is necessary to improve pregnancy state. According to the mentioned statements, the researcher question is: Is there a difference between the primiparous and multiparous women in resilience, cognitive emotion regulation, and metacognitive believes?

\section{Materials and Methods}

The current research was a cross-sectional analytic study. The participants of this research consist of all primiparous and multiparous women who referred to Rasht hospitals between June and October in 2016 (including 700 women). One hundred and twenty persons (60 primiparous women and 60 multiparous women) selected by the random clustering sampling method. In the beginning, 5 hospitals, ten women $\&$ maternity clinics selected, then subjects were selected by a simple random method. Two groups matched in terms of age, sex, and educational status. Before executing research and giving questionnaires, the necessary information has given to all students about the research subject, and all stated their satisfaction. Also, all of them became assured of being secretive about their information. The Connor-Davidson resilience scale assessed women, Cognitive emotion regulation questionnaire by Granfsky et al (2004), and Wells et al metacognition questionnaire (2004).

\section{Connor-Davidson Resilience Scale (CD-RISC)}

This scale designed by Connor and Davidson and consists of 25 items each rated on a 5-point scale (0-4), with higher scores reflecting greater resilience. All of which carry a 5-point range of responses, as follows: not true at all (0), rarely true (1), sometimes true (2), often true (3), and true nearly all of the time (4). The scale is rated based on how the subject has felt over the past month. The total score ranges from $0-100$, with higher scores reflecting greater resilience. Connor and Davidson have reported Cronbach's- $\alpha$ coefficient of resilience scale 0.89 , reliability coefficient $0.87 .{ }^{15}$ In Iran, Mohammadi et al have reported the reliability of the scale of $0.89 .{ }^{16}$ The reliability of this questionnaire has been evaluated by 0.72 by Cronbach's- $\alpha$ method in this research.

\section{Cognitive Emotion Regulation Questionnaire}

Garnefski et al designed this questionnaire in 2001. ${ }^{17}$ It is one self-report tool, including 36 items with nine dimensions. The scoring method of this questionnaire based on 5 degrees Likert scale from 1 (Never) until 5 (Always). All 4 questions evaluate one factor, and the minimum and maximum scores for each sub-scale are 4 and 20, respectively, and the higher score indicates a person's better performance. The Cronbach's- $a$ coefficient for the subscales of this questionnaire has been reported by Garnefski et al in the range of 0.71 to $0.81 .{ }^{18}$ The reliability and validity of this questionnaire have been reported acceptable in the Iranian clinical population. ${ }^{19}$

\section{Metacognition Questionnaire}

The short form of Wells metacognition Questionnaire (MCQ-30) is one self-report with 30 items and 5 subscales, which was designed by Wells in 1997 and studied a person's beliefs about their thoughts. ${ }^{20}$ Responses calculated based on a 4 -point Likert scale ( 1 disagree to 4 agreed on a lot). Wells and Cartwright-Hatton ${ }^{20}$ reported that the reliability of this range of Cronbach's alpha coefficients for the whole scale and subscales ranged from 0.76 to 0.93 , and test-retest reliability was 0.75 and for the subscales of 0.59 to 0.87 . Cronbach's a coefficient of the total scale has been stated 0.91 in the Iranian sample. ${ }^{21}$

\section{Statistical Analysis}

In the descriptive part, the mean and standard deviation has used. The Kolmogorov-Smirnov test was used to check the normality of data. Data analysis has gathered by using the multivariate variance analysis. All analyses performed with software SPSS version 22 software.

\section{Results}

A total of 120 married women (60 primiparous women and 60 multiparous women) investigated. The mean and standard deviation of age in the primiparous and multiparous women groups were $28.01 \pm 4.28$ and $28.89 \pm 5.68$ orderly. Also, based on educational status, 2 groups were included an eight-under diploma, 18 diplomas, $50 \mathrm{BA}$, and $44 \mathrm{MA}$.

The mean and standard deviation of resilience, cognitive emotion regulation, and metacognitive beliefs of primiparous and multiparous women have stated in Table 1.

As per Kolmogorov-Smirnov test results, data indicate normal distribution. According to the significance level, there is a difference among resilience, cognitive regulation of emotion, and metacognitive beliefs of primiparous and multiparous women $(P<0.001)$ (Table 2$)$.

According to the results of Table 3 , the difference in resilience between primiparous and multiparous women groups was statistically significant $(\mathrm{F}=15.7, P<0.001)$. It indicates that multiparous women show more resilience than primiparous. Also, there are a significant difference between 2 groups among self-blame $(\mathrm{F}=14.49, P<0.001)$, others blaming $(\mathrm{F}=11.42, \quad P<0.001), \quad$ rumination $(\mathrm{F}=12.72, P<0.001)$, catastrophizing $(\mathrm{F}=89.44, P<0.001)$, putting into perspective $(\mathrm{F}=35.36, P<0.001)$, positive refocusing $(\mathrm{F}=20.74, \quad P<0.001)$, positive reappraisal $(\mathrm{F}=39.07, \quad P<0.007)$, acceptance $(\mathrm{F}=19.19, \quad P<0.001)$ and refocus on planning $(\mathrm{F}=10.66, P<0.001)$. It means that multiparous women had better performance in 
Table 1. Descriptive Indicators of Study Variables

\begin{tabular}{|c|c|c|c|c|}
\hline Variables & & Group & Mean & SD \\
\hline \multirow{2}{*}{ Resilience } & \multirow{2}{*}{ Resilience } & Multiparous & 45.84 & 9.06 \\
\hline & & Primiparous & 41.71 & 5.77 \\
\hline \multirow{18}{*}{$\begin{array}{l}\text { Cognitive } \\
\text { Emotion } \\
\text { Regulation }\end{array}$} & \multirow{2}{*}{ Self-blame } & Multiparous & 12.47 & 2.41 \\
\hline & & Primiparous & 14.19 & 3.99 \\
\hline & \multirow{2}{*}{ Others blaming } & Multiparous & 11.65 & 3.12 \\
\hline & & Primiparous & 13.17 & 3.21 \\
\hline & \multirow{2}{*}{ Rumination } & Multiparous & 13.11 & 3.75 \\
\hline & & Primiparous & 15.04 & 4.12 \\
\hline & \multirow{2}{*}{ Catastrophizing } & Multiparous & 12.16 & 3.02 \\
\hline & & Primiparous & 15.94 & 2.69 \\
\hline & \multirow{2}{*}{ Putting into perspective } & Multiparous & 13.09 & 2.68 \\
\hline & & Primiparous & 10.66 & 2.93 \\
\hline & \multirow{2}{*}{ Positive refocusing } & Multiparous & 15.23 & 3.29 \\
\hline & & Primiparous & 13.06 & 3.65 \\
\hline & \multirow{2}{*}{ Positive reappraisal } & Multiparous & 15.04 & 8.02 \\
\hline & & Primiparous & 13.17 & 2.52 \\
\hline & \multirow{2}{*}{ Acceptance } & Multiparous & 14.85 & 4.18 \\
\hline & & Primiparous & 12.52 & 3.52 \\
\hline & \multirow{2}{*}{ Refocus on planning } & Multiparous & 14.31 & 3.19 \\
\hline & & Primiparous & 11.57 & 3.65 \\
\hline \multirow{10}{*}{ Metacognition } & \multirow{2}{*}{$\begin{array}{l}\text { Positive beliefs about } \\
\text { worry }\end{array}$} & Multiparous & 51.81 & 17.08 \\
\hline & & Primiparous & 46.01 & 14.63 \\
\hline & \multirow{2}{*}{$\begin{array}{l}\text { Negative beliefs about } \\
\text { the uncontrollability of } \\
\text { thought }\end{array}$} & Multiparous & 43.07 & 19.67 \\
\hline & & Primiparous & 32.59 & 13.34 \\
\hline & \multirow{2}{*}{ Cognitive confidence } & Multiparous & 27.96 & 9.83 \\
\hline & & Primiparous & 29.31 & 10.37 \\
\hline & \multirow{2}{*}{$\begin{array}{l}\text { Beliefs about the need } \\
\text { to control thoughts }\end{array}$} & Multiparous & 30.48 & 7.84 \\
\hline & & Primiparous & 29.22 & 7.32 \\
\hline & \multirow{2}{*}{$\begin{array}{l}\text { Cognitive self- } \\
\text { consciousness }\end{array}$} & Multiparous & 25.49 & 7.87 \\
\hline & & Primiparous & 30.49 & 9.99 \\
\hline
\end{tabular}

Table 2. The Results of Lambda Wilks Test for Comparing Resiliency, Cognitive Emotion Regulation and Metacognitive Beliefs in Primiparous and Multiparous Women

\begin{tabular}{lccccc}
\hline Test & Value & F & df & df Error & $P$ Value \\
\hline Pillai's trace & 0.6111 & 20.54 & 15 & 196 & 0.001 \\
Wilks lambda & 0.389 & 20.54 & 15 & 196 & 0.001 \\
Hotelling trace & 1.57 & 20.54 & 15 & 196 & 0.001 \\
Roy's largest root & 1.57 & 20.54 & 15 & 196 & 0.001 \\
\hline
\end{tabular}

self-blame, others blaming, rumination, catastrophizing, putting into perspective, positive refocusing, positive reappraisal, acceptance, and refocus on planning than primiparous women.

As seen in Table 3, there are significant difference between primiparous and multiparous women among positive beliefs about worry $(\mathrm{F}=7.06, P<0.001)$, negative beliefs about uncontrollability of thought $(\mathrm{F}=20.67$, $P<0.001)$ and cognitive self-consciousness ( $\mathrm{F}=16.40$, $P<0.001$ ), while there was no significant difference between the 2 groups in cognitive confidence and beliefs about need to control thoughts $(P>0.05)$. Therefore, multiparous women show firmer positive beliefs about worry and negative beliefs about the uncontrollability of thought than primiparous. Also, primiparous women have higher cognitive self-awareness than multiparous women.

\section{Discussion}

The aim of the present research is a comparison of resilience, cognitive emotion regulation, and metacognitive beliefs of primiparous women and multiparous women. The findings showed that there are differences in resilience, cognitive emotion regulation, and metacognitive beliefs between primiparous women and multiparous women. This result is consistent with the findings of several studies., ${ }^{5,22-25}$ In explaining these results, we can say, during each woman's life, some steps have profound effects on her life. The pregnancy period is a critical stage with physiological and psychological changes. Despite the pleasure of being a mother, it sometimes comes with stress and extreme fears. Even first childbirth stress classified as severe stress at mental-social stress tables. Multiparous women are more resilience than primiparous women, due to previous experiences in childbirth and more information that they already have. They can solve their stress with positive strategies and also have more flexibility in dealing with problems. The people with higher resilience have a high positive performance in adverse conditions. Therefore, it is more resistant to various problems, and the quality of life will be higher in this situation. ${ }^{3,26}$ The results showed that there is a difference between primiparous and multiparous women in the mean of cognitive, emotional regulation, multiparous women have positive refocusing, acceptance, refocus on planning, positive reappraisal, and higher putting into perspective than primiparous women. Also, primiparous women have more self-blame, others blaming, rumination, and catastrophizing than multiple women. In explaining this finding, it seems that when people feel that they do not have control over their lives and events, they show depression, stress and anxiety more often and this leads to a sense of disability and the lack of relief from problems and a solution that is somehow a passive person susceptible to depression. People with weak cognitive strategies such as rumination, catastrophizing, and blaming are more vulnerable to emotional problems than others, while those with desirable strategies such as positive refocusing, acceptance, and refocus on planning, they are less vulnerable. ${ }^{27}$ Using of maladaptive strategies makes an individual vulnerable to anxiety instead of responding appropriately to stressful events, while adaptive strategies do not follow these outcomes. Managing self-emotions and others leads to the power of organizing and adapting the person in stimulating situations. Emotion management may increase person adjustment ability in stimulating situations. The person with improved emotion management can experience 
Table 3. Comparison of the Resilience, Cognitive Emotion Regulation and Metacognitive Beliefs Between Primiparous and Multiparous Women

\begin{tabular}{|c|c|c|c|c|c|}
\hline Changes Resources & Sum Squares & $d f$ & Mean Squares & $\mathbf{F}$ & $P$ Value \\
\hline \multirow{2}{*}{$\begin{array}{l}\text { Resilience } \\
\text { Error }\end{array}$} & 902.98 & 1 & 902.98 & \multirow{2}{*}{15.7} & \multirow{2}{*}{0.001} \\
\hline & 12076.27 & 210 & 57.51 & & \\
\hline \multirow{2}{*}{$\begin{array}{l}\text { Self-blame } \\
\text { Error }\end{array}$} & 158.54 & 1 & 158.54 & \multirow{2}{*}{14.49} & \multirow{2}{*}{0.001} \\
\hline & 12076 & 210 & 57.51 & & \\
\hline \multirow{2}{*}{$\begin{array}{l}\text { Others blaming } \\
\text { Error }\end{array}$} & 122.54 & 1 & 122.54 & \multirow{2}{*}{11.42} & \multirow{2}{*}{0.001} \\
\hline & 2253.93 & 210 & 10.73 & & \\
\hline \multirow{2}{*}{$\begin{array}{l}\text { Rumination } \\
\text { Error }\end{array}$} & 197.94 & 1 & 197.94 & \multirow{2}{*}{12.72} & \multirow{2}{*}{0.001} \\
\hline & 32667.69 & 210 & 10.56 & & \\
\hline \multirow{2}{*}{$\begin{array}{l}\text { Catastrophizing } \\
\text { Error }\end{array}$} & 758.03 & 1 & 758.03 & \multirow{2}{*}{89.44} & \multirow{2}{*}{0.001} \\
\hline & 1779.91 & 210 & 8.48 & & \\
\hline \multirow{2}{*}{$\begin{array}{l}\text { Putting into perspective } \\
\text { Error }\end{array}$} & 313.37 & 1 & 313.37 & \multirow{2}{*}{35.36} & \multirow{2}{*}{0.001} \\
\hline & 1860.94 & 210 & 8.86 & & \\
\hline \multirow{2}{*}{$\begin{array}{l}\text { Positive refocusing } \\
\text { Error }\end{array}$} & 250.12 & 1 & 250.12 & \multirow{2}{*}{20.74} & \multirow{2}{*}{0.001} \\
\hline & 2532.18 & 210 & 12.06 & & \\
\hline \multirow{2}{*}{$\begin{array}{l}\text { Positive reappraisal } \\
\text { Error }\end{array}$} & 263.96 & 1 & 263.96 & \multirow{2}{*}{39.03} & \multirow{2}{*}{0.007} \\
\hline & 1420.17 & 210 & 6.76 & & \\
\hline \multirow{2}{*}{$\begin{array}{l}\text { Acceptance } \\
\text { Error }\end{array}$} & 286.29 & 1 & 286.29 & \multirow{2}{*}{19.19} & \multirow{2}{*}{0.001} \\
\hline & 3132.25 & 210 & 14.92 & & \\
\hline \multirow{2}{*}{$\begin{array}{l}\text { Refocus on planning } \\
\text { Error }\end{array}$} & 399.09 & 1 & 399.09 & \multirow{2}{*}{10.66} & \multirow{2}{*}{0.001} \\
\hline & 7858.85 & 210 & 37.42 & & \\
\hline \multirow{2}{*}{$\begin{array}{l}\text { Positive beliefs about worry } \\
\text { Error }\end{array}$} & 1782.87 & 1 & 1782.87 & 706 & 0.001 \\
\hline & 53021.14 & 210 & 252.48 & 1.00 & 0.001 \\
\hline Negative beliefs about the uncontrollability of thought & 5818.14 & 1 & 5818.14 & 20.67 & 0.001 \\
\hline Error & 59102.44 & 210 & 281.44 & 20.08 & 0.001 \\
\hline Cognitive confidence & 96.09 & 1 & 96.09 & 0.94 & 0.33 \\
\hline & 21442.67 & 210 & 102.11 & & \\
\hline Beliefs a bout the need to control thourats & 83.06 & 1 & 83.06 & & \\
\hline betress about the need to contror thougnts & 12068.81 & 210 & 57.47 & 1.45 & 0.23 \\
\hline Coonitive self-consciousness & 1329.98 & 1 & 1329.98 & 1640 & 0001 \\
\hline cogmine sen-consciousmess & 17034.98 & 210 & 81.12 & 10.40 & 0.001 \\
\hline
\end{tabular}

emotions or prevents them from any external and internal pressure. The inability to regulate emotions make one's emotions more dominant and logical and the individual in different situations only by relying on the emotional atmosphere of the environment and without considering any logical solutions possible. ${ }^{7}$ Based on findings, multiparous women show firmer positive beliefs about worry and negative beliefs about the uncontrollability of thought than primiparous. Also, primiparous women have higher cognitive self-awareness than multiparous women. This result is consistent with the finding of Delavar Gavam and Alizadeh Goradel research. ${ }^{22}$ In explaining this hypothesis, it can point out that many mental and psychological disorders of pregnant women are related to women's unconscious of the natural changes in their bodies and mental due to the pregnancy. Primiparous women have a higher awareness due to their positive experiences in the first pregnancy. However, multiparous women will have worries, and negative beliefs lead to conflicts of life, having other children, and having other problems compared to primiparous women. Most people who have positive beliefs about worries believe that the concern helps to solve the problem and increases their motivation, and being concerned about this kind of person is considered as a positive personality trait.

Consequently, meta-cognitive beliefs make people feel less self-controlled and, as a result, have anxiety and depression. ${ }^{28}$ On the other hand, meta-cognitive beliefs of uncontrollability and risk make people more skeptical about their abilities, which can be due to individual experiences in terms of life and various stages of life. ${ }^{29}$ One of the limitations of this study was using a questionnaire to gather data, and it may result in creating an unconscious orientation for many respondents. Also, this study has executed in Rasht province. Therefore we are cautious about generalizing results to the other cities.

\section{Conclusion}

Finally, in conclusion, the results showed significant differences in primiparous and multiparous women in resiliency, cognitive emotion regulation, and metacognitive beliefs, which can take necessary training and active steps in their promotion. 


\section{Conflict of Interest Disclosures}

The authors declare that they have no conflict of interests.

\section{Ethical Statement}

Before executing research and giving questionnaires, the necessary information has given to all students about the research subject, and all stated their satisfaction. Also, all of them became assured of being secretive about their information.

\section{References}

1. Sheraton A, Streckfuss J, Grace S. Experiences of pregnant women receiving osteopathic care. J Bodyw Mov Ther. 2018;22(2):321-7. doi: 10.1016/j.jbmt.2017.09.007.

2. Eggebø TM, Heien C, Okland I, Gjessing LK, Smedvig E, Romundstad $\mathrm{P}$, et al. Prediction of labour and delivery by ascertaining the fetal head position with transabdominal ultrasound in pregnancies with prelabour rupture of membranes after 37 weeks. Ultraschall Med. 2008;29(2):17983. doi: 10.1055/s-2007-963017.

3. Yazdi-Ravandi S, Taslimi Z, Saberi H, Shams J, Osanlo S, Nori G, et al. The role of resilience and age on quality of life in patients with pain disorders. Basic Clin Neurosci. 2013:4(1):24-30.

4. Werner EE, Smith RS. Overcoming the odds: high risk children from birth to adulthood. London: Cornell University Press; 1992.

5. Shebi K, Ghafari O. Comparison of endurance between pregnant \& unpregnant women in city of Khoy 1 st congress of society making powerful in social sciences. Tehran: Institute of Psychology and Educational Sciences; 2015.

6. Modaress M, Mirmolaie S, Rahimikian F, Afrasiabie S. An epidemiologic assessment of post traumatic stress disorder following childbearing. Hayat. 2011;16(3-4):66-76. [Persian].

7. Williams LE, Bargh JA, Nocera CC, Gray JR. The unconscious regulation of emotion: nonconscious reappraisal goals modulate emotional reactivity. Emotion. 2009;9(6):847-54. doi: 10.1037/a0017745.

8. Weilenmann S, Schnyder U, Parkinson B, Corda C, von Känel R, Pfaltz MC. Emotion transfer, emotion regulation, and empathy-related processes in physician-patient interactions and their association with physician well-being: a theoretical model. Front Psychiatry. 2018;9:389. doi: 10.3389/ fpsyt.2018.00389.

9. Ochsner KN, Gross JJ. The cognitive control of emotion. Trends Cogn Sci. 2005;9(5):242-9. doi: 10.1016/j.tics.2005.03.010.

10. Hasani J, Azadfalah P, Rasoulzade Tabatabaei K, Ashayeri H. The assessment of cognitive emotion regulation strategies according to neuroticism and extraversion personality dimensions. Advances in Cognitive Science. 2009;10(4):1-13. [Persian].

11. Troy AS, Mauss IB. Resilience in the face of stress: emotion regulation as a protective factor. In: Southwick S, Litz B, Charney D, Friedman M, eds. Resilience and Mental Health: Challenges Across the Lifespan. Cambridge: Cambridge University Press; 2011. p. 30-44. doi: 10.1017/ CBO9780511994791.004.

12. Wells A. Emotional disorders and metacognition: innovative cognitive therapy. New York: John Wiley \& Sons; 2002.

13. Wells A. Metacognitive therapy for anxiety and depression. New York: Guilford Press; 2011.

14. Yılmaz AE, Gençöz T, Wells A. The temporal precedence of metacognition in the development of anxiety and depression symptoms in the context of life-stress: a prospective study. J Anxiety Disord. 2011;25(3):389-96. doi: 10.1016/j. janxdis.2010.11.001.

15. Connor KM, Davidson JR. Development of a new resilience scale: the Connor-Davidson Resilience Scale (CD-RISC). Depress Anxiety. 2003;18(2):76-82. doi: 10.1002/da.10113.

16. Mohammadi M, Jazayeri AR, Rafiei AH, Jokar B, Pourshahbaz A. Study of the resiliency factors in people at risk of drug abuse. Journal of Modern Psychological Researches. 2006;1(2-3):193-214

17. Garnefski N, Kraaij V, Spinhoven P. Negative life events, cognitive emotion regulation and emotional problems. Pers Individ Dif. 2001;30(8):1311-27. doi: 10.1016/S01918869(00)00113-6.

18. Garnefski N, van den Kommer TN, Kraaij V, Teerds J, Legerstee J, Onstein E. The relationship between cognitive emotion regulation strategies and emotional problems: comparison between a clinical and a non-clinical sample. Eur J Pers. 2002;16(5):403-20. doi: 10.1002/per.458.

19. Besharat MA, Bazzazian S. Psychometri properties of the Cognitive Emotion Regulation Questionnaire in a sample of Iranian population. Advances in Nursing \& Midwifery. 2015;24(84):61-70.

20. Wells A, Cartwright-Hatton S. A short form of the metacognitions questionnaire: properties of the MCQ-30. Behav Res Ther. 2004;42(4):385-96. doi: 10.1016/s00057967(03)00147-5.

21. Shirinzadeh Dastgiri S, Gudarzi MA, Ghanizadeh A, Taghavi SMR. Comparison of metacognitive and responsibility beliefs in patients with obsessive-compulsive disorder, generalized anxiety disorder and normal individuals. Iranian Journal of Psychiatry and Clinical Psychology. 2008;14(1):46-55. [Persian].

22. Delavar Gavam S, Alizadeh Goradel J. The role of metacognitive beliefs and positive and negative affect in the Fear of childbirth of pregnant women with first experience. Iranian Journal of Nursing Research. 2014;9(3):10-8. [Persian].

23. Ryding EL, Wirfelt E, Wängborg IB, Sjögren B, Edman G. Personality and fear of childbirth. Acta Obstet Gynecol Scand. 2007;86(7):814-20. doi: 10.1080/00016340701415079.

24. Khodabakhshi Koolaee A, Heidari S, Khoshkonesh A, Heidari $M$. Relationship between spiritual intelligence and resilience to stress in preference of delivery method in pregnant women. The Iranian Journal of Obstetrics, Gynecology and Infertility. 2013;16(58):8-15. doi: 10.22038/ijogi.2013.1470. [Persian].

25. Christiaens W, Bracke P. Assessment of social psychological determinants of satisfaction with childbirth in a cross-national perspective. BMC Pregnancy Childbirth. 2007;7:26. doi: 10.1186/1471-2393-7-26.

26. Shayan A, Masoumi SZ, Yazdi-Ravandi S, Zarenezhad M. Factors affecting spouse abuse in women referred to the Shiraz legal medicine center in 2013. Pajouhan Scientific Journal. 2015;14(1):39-48. [Persian].

27. Garnefski N, Kraaij V. The cognitive emotion regulation questionnaire. Eur J Psychol Assess. 2007;23(3):141-9.

28. Biaggi A, Conroy S, Pawlby S, Pariante CM. Identifying the women at risk of antenatal anxiety and depression: A systematic review. J Affect Disord. 2016;191:62-77. doi: 10.1016/j.jad.2015.11.014

29. Cotter J, Yung AR, Carney R, Drake RJ. Metacognitive beliefs in the at-risk mental state: A systematic review and metaanalysis. Behav Res Ther. 2017;90:25-31. doi: 10.1016/j. brat.2016.12.004. 